\title{
Fibre bridging and nozzle clogging in 3D printing of discontinuous carbon fibre-reinforced polymer composites: coupled CFD-DEM modelling
}

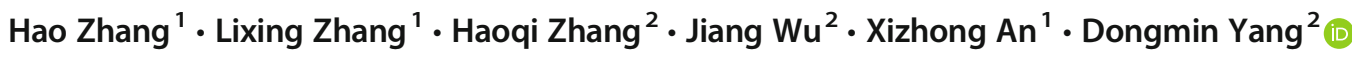 \\ Received: 18 April 2021 / Accepted: 19 August 2021 / Published online: 31 August 2021 \\ (C) The Author(s) 2021
}

\begin{abstract}
A coupled multiphase model based on computational fluid dynamics (CFD) and discrete element method (DEM) is developed to numerically investigate the extrusion-based 3D printing process of discontinuous carbon fibre-reinforced polymer composites. Short carbon fibres are modelled as rigid bodies by clumping discrete spheres in DEM, while polymer matrix is treated as an incompressible Newtonian fluid in CFD. A fluid-particle interaction model is adopted to couple DEM and CFD and represent the dynamic fibre/matrix interaction. Collisions between fibres are considered naturally in DEM by using the Hertz-Mindlin contact law. The coupled CFD-DEM is validated, both qualitatively and quantitatively, against X-ray microtomography $(\mu \mathrm{CT})$ experimental results for the T300/PA6 composite. Parametric study on various fibre lengths, fibre volume fraction and resin viscosity using the CFD-DEM model shows that the nozzle clogging tends to occur when the fibre length and/or the fibre volume fraction are increased. Use of a polymer matrix with a lower viscosity can be effective to eliminate the clogging issue when printing composites with relatively short fibres. The fibre length is dominating when long fibres are used and the clogging is largely independent on the viscosity of the polymer matrix. Finally, a potential solution of using a cone sleeve insert located above the shrinking region to address the nozzle clogging issue is proposed and numerically assessed.
\end{abstract}

Keywords 3D printing · Computational fluid dynamics · Discrete element method · Carbon fibre-reinforced polymer composites · Nozzle clogging

\section{Introduction}

Carbon fibre-reinforced polymer (CFRP) composites offer various advantages such as high strength and high stiffness-to-weight ratio, as well as excellent fatigue performance and corrosion resistance $[1,2]$. Apart from the traditional manufacturing methods, the recently emerged additive manufacturing techniques ( $\mathrm{AM}$, also known as 3D printing) have shown the potential to enable low-cost and mould-free manufacturing of threedimensional objects with complex geometries [3]. Among them,

Dongmin Yang

Dongmin.Yang@ed.ac.uk

1 Key Laboratory for Ecological Metallurgy of Multimetallic Mineral of Ministry of Education, School of Metallurgy, Northeastern University, Shenyang 110819, People's Republic of China

2 Institute for Materials and Processes, School of Engineering, University of Edinburgh, Edinburgh EH9 3FB, UK the extrusion-based fused filament fabrication (FFF) printing is the most popular process (by number of machines), which fabricates a part by melting and depositing the composite material layer by layer [4]. Due to the favourable melt processability, a wide variety of thermoplastic can be used as the matrix materials in the FFF 3D printing of composites, such as acrylonitrile butadiene styrene plastic (ABS), polylactic acid (PLA) and nylon. Discontinuous carbon fibres are usually introduced to reinforce thermoplastics in order to improve its strength, stiffness and heat resistance [5]. Previous researches have shown that improved mechanical properties can be achieved in the printed composites [6], in particular the flexural properties could be improved by 2 3 times with the mixed discontinuous carbon fibres [7].

Thermoplastic polymers have a relatively higher melt viscosity than thermosetting polymers and it is challenging to form strong bonds between a thermoplastic polymer and carbon fibres. The chopped carbon fibres mixed in the melt thermoplastic during FFF printing would further increase the viscosity, and the difference in their coefficients of thermal 
expansion would result in more voids during the heat cycling $[6,8,9]$. Although manufacturing of short fibre composites at a faster production rate is desirable with the FFF technique, if not well treated, the mechanical properties of finished parts could be impaired and even become inferior to that of the printed neat polymer materials, which is mainly caused by the voids formed in the printing process [10]. On the other hand, the chopped carbon fibres currently used in the 3D printing are usually shorter than $0.2 \mathrm{~mm}$, which is not long enough to make a distinctive enhancement on the mechanical properties of the printed composites. Markforged $®$ reported that the tensile properties of discontinuous fibre-reinforced thermoplastic composites are lower than the 3D-printed neat thermoplastic.

Attempting to address the afore-mentioned issues, the mechanisms of the melt flow as well as void formation through the standard FFF printing process have been investigated [11]. Previous researches have studied the effect of printing parameters on the mechanical performance [12-15]. And the in situ consolidation techniques such as ultrasonic vibration [16] and post printing treatment such as hotpressing [17] have been adopted to remove the air voids induced during the printing. In order to achieve higher mechanical performance, other attempts have been made such as the use of longer discontinuous fibres (e.g. $3 \mathrm{~mm}$ ) in previous work [18]. A few studies also aimed to customise the alignment of discontinuous fibres in the composites with the nozzle design and path optimization [19-21], in addition to rotational printing [22] and the use of a magnetic field [23]. Another extrusion-based printing technique, direct-ink writing (DIW), has been used to print short fibre-reinforced polymer composites, in which a thermosetting resin with low viscosity is mixed with the short carbon fibres prior to the printing [20]. In the DIW printing process, a long and needle-like nozzle is usually adopted, but risks of fibre bridging and nozzle clogging still exist in the regions close to the nozzle outlet when long fibres are used [24].

Due to the lack of understanding on fibre motion and distribution as well as the interaction among them, the mechanism for the issues of fibre breakage and nozzle clogging is still unclear. This also imposes a major constraint on the additive manufacturing of composites with longer discontinuous fibres and tailored fibre orientation during printing. In addition, the large variability of printing parameters results in inconsistent properties of the deposited composites. Optimal printing parameters are usually identified through a nontrivial trial-and-error process for each specific composite, followed by traditional tensile/flexural tests and the characterisation of fracture profile $[12,25]$. Therefore, there is still a lack of established process-properties relationship for 3D printing of composites in general.

Computational modelling, as an alternative research tool, can provide much more details of multiphase flow which are hardly accessible via traditional physical measurement and thus has been adopted to improve the understanding of the 3D printing process [26]. Papon et al. [27] developed a computational model and numerically investigated the effects of nozzle speed, feed rate and nozzle geometry on the mechanical performance of 3D-printed composites. Finite element method (FEM) was also used to evaluate the polymer melt flow and the associated effects of nozzle geometry and extrudate swell on fibre orientation [28]. The effective bulk mechanical properties, specifically the longitudinal and transverse moduli, and the coefficient of thermal expansion were calculated for the deposited bead based on the spatially varying fibre orientation tensors [29]. Yang et al. [30] established a new coupling model based on smoothed particle hydrodynamics (SPH) and discrete element method (DEM) to simulate the 3D printing process of short CFRP composites and obtained promising results for the rheological flow and fibre orientation.

From the literature survey, it is still necessary to further understand (and eventually better control) the flow characteristics of the melt composites during the 3D printing process. Numerical simulations with rigorous validations would be useful to achieve this target. Unfortunately, modelling such multiphysics, multiphase flow process is complicated and there have been very few studies yet. Croom et al. [24] used computational fluid dynamics (CFD) to simulate the resin flow in DIW 3D printing process. However, fibres were not explicitly considered in the model and fibre-fibre collisions could not be fully represented; thus, the nozzle clogging was not well addressed. The fibre-fibre collision behaviours were captured in the SPH-DEM model by Yang et al. [30], but the fibre length is very short and the occurrence of nozzle clogging was investigated due to the fact that the model was two dimensional. On the other hand, experimental validation of such numerical models is very challenging and has been rarely reported in the literature, as it is difficult to observe the fibre orientation and distribution during the printing process, especially for those areas inside the extrude nozzle.

Therefore, this study aims to develop a 3D coupled model based on CFD and DEM to understand the effects of printing parameters, including fibre volume fraction $\left(V_{f}\right)$, fibre length and matrix viscosity, on the fibre misalignment and nozzle clogging in extrusion-based 3D printing of composites. The original contribution of the current work include the following: (a) a novel CFD-DEM model is established and validated by the experimental data to investigate the $3 \mathrm{D}$ printing process of carbon fibre-reinforced polymer composites. The main advantage of the CFD-DEM model is its computational efficiency which enables the simulation of a large amount of individual fibres in the printing process; (b) occurrence of nozzle clogging is predicted with governing mechanisms discussed; and (c) potential solutions to prevent nozzle clogging are provided. The paper is organised as follows. 'Section 2' 
introduces the numerical methods for the coupled CFD-DEM model and its validation, followed by comprehensive parametric studies in 'Section 3'. Potential solutions are proposed and numerically assessed in 'Section 4'. Conclusions are finally drawn in 'Section 5'.

\section{Coupled CFD-DEM modelling and validations}

\subsection{CFD-DEM coupling}

In the coupled CFD-DEM model, short fibres are regarded as a discrete, solid phase and simulated using DEM, while the polymer matrix is simulated using CFD. As the short fibres normally have an aspect ratio larger than one, each fibre is represented by a group of discrete DEM particles that are bonded together as a rigid clump. The motion of each particle in DEM is described by Newton's second law of motion. For particle $i$, the equations governing the translational and rotational motions can be expressed as:

$m_{i} \frac{d}{d t} v_{i}=\mathrm{F}_{p f, i}+\sum_{j=1}^{n_{i}}\left(\mathrm{~F}_{e, i j}+\mathrm{F}_{d, i j}\right)+m_{i} \mathrm{~g}$

$I_{i} \frac{d}{d t} \omega_{i}=\sum_{j=1}^{n_{i}}\left(\mathrm{~T}_{t, i j}+\mathrm{T}_{r, i j}+\mathrm{T}_{n . i j}\right)$

where $m_{i}$ and $I_{i}$ are the particle mass and the moment of inertia, respectively. $v_{i}$ and $\omega_{i}$ are the linear and angular velocities, respectively. $n_{i}$ is the number of particles interacting with particle $i$. Relevant forces are gravitational force $m_{i} \boldsymbol{g}$, fluid-particle interaction force $\boldsymbol{F}_{p f, i}$ and inter-particle collision forces including elastic force $\boldsymbol{F}_{e, i j}$ and viscous damping force $\boldsymbol{F}_{d, i j}$. The Hertz-Mindlin contact model is adopted to calculate the inter-particle collision force. The torques acting on particle $i$ by particle $j$ include $\boldsymbol{T}_{t, i j}$ generated by the tangential force, $\boldsymbol{T}_{r, i j}$ known as the rolling friction torque and $\boldsymbol{T}_{n, i j}$ generated when the normal force does not pass through the centre of particle $i$.

The polymer matrix is regarded as a continuous phase whose motion follows the Navier-Stokes equations given by:

$$
\begin{aligned}
& \frac{\partial}{\partial t}\left(\varepsilon \rho_{f}\right)+\nabla \cdot\left(\varepsilon \rho_{f} \mathbf{u}_{f}\right)=0 \\
& \frac{\partial}{\partial t}\left(\varepsilon \rho_{f} \mathbf{u}_{f}\right)+\nabla \cdot\left(\varepsilon \rho_{f} \mathbf{u}_{f} \mathbf{u}_{f}\right)=-\nabla p+\nabla \cdot \tau+\varepsilon \rho_{f} \mathbf{g}-\mathbf{F}_{f p}
\end{aligned}
$$

where $\rho_{f}$ is fluid density, $t$ is time, $\boldsymbol{u}_{f}$ is fluid velocity and $p$ is fluid pressure. $\varepsilon=1-\sum_{i=1}^{k_{v}} V_{i} / \Delta V$ is the voidage where $k_{v}$ is the total number of particles in the current computational cell of volume $\Delta V$ and $V_{i}$ is the volume of particle $i$. $\tau$ is the stress tensor which is given as follows: $\tau=\mu_{f}\left[\left(\nabla \mathrm{u}_{f}\right)+\left(\nabla \mathrm{u}_{f}\right)^{-1}\right]-$
$(2 / 3) \mu\left(\nabla \cdot \mathrm{u}_{f}\right) \delta_{k}$, where $\mu$ is fluid dynamic viscosity and $\delta_{k}$ is the fluid Kronecker delta. At last, $\mathrm{F}_{f p}=\left(\sum_{i=1}^{k_{v}} \mathrm{~F}_{p f, i}\right) / \Delta V$ is the volumetric fluid-particle interaction force.

The drag force is the only fluid-particle interaction force considered in this study, which can be described as:

$\mathrm{F}_{p f, i}=V_{i} \beta\left(\mathrm{u}_{f}-\mathrm{v}_{i}\right) /(1-\varepsilon)$

where $\beta$ is the fluid-particle interphase drag coefficient [31] and can be defined as:

$$
\beta= \begin{cases}150 \frac{(1-\varepsilon)^{2} \mu_{f}}{\varepsilon^{2} d_{p, i}^{2}}+1.75 \frac{(1-\varepsilon) \rho_{f}}{\varepsilon d_{p, i}}\left|\mathrm{u}_{f}-\mathrm{v}_{i}\right| & \varepsilon<0.8 \\ \frac{3}{4} C_{D} \frac{(1-\varepsilon) \rho_{f}}{d_{p, i}}\left|\mathrm{u}_{f}-\mathrm{v}_{i}\right| \varepsilon^{-2.65} & \varepsilon \geq 0.8\end{cases}
$$

where $d_{p, i}$ is the diameter of particle $i . C_{D}$ is the drag coefficient, which can determine the effective transfer of the interphase force. The formula has considered the effect of the particle shape using the concept of sphericity $\varphi$, as given by:

$$
\begin{aligned}
C_{D}=\frac{24}{\operatorname{Re}_{i}}(1 & \left.+\exp \left(2.33-6.46 \varphi+2.45 \varphi^{2}\right) \operatorname{Re}_{i}^{0.10+0.56 \varphi}\right) \\
& +\frac{\exp \left(4.91-13.89 \varphi+18.42 \varphi^{2}-10.26 \varphi^{3}\right) \operatorname{Re}_{i}}{\exp \left(1.47+12.26 \varphi-20.73 \varphi^{2}+15.91 \varphi^{3}\right)+\operatorname{Re}_{i}}
\end{aligned}
$$

where $R e_{i}=\varepsilon \rho_{f} d_{v}\left|\mathrm{u}_{f}-\mathrm{v}_{i}\right| / \mu_{f}$ is the Reynolds number for particle $i . d_{v}$ is the equivalent diameter defined as the diameter of a sphere with the same volume as the non-spherical particle. Therefore, $d_{p, i}=d_{v}$ in this study.

All the numerical simulations were carried out on the working station with Intel Xeon Gold 6126 24-core $2.6 \mathrm{GHz}$ and $2.59 \mathrm{GHz}$ (2 processors), $80 \mathrm{~GB}$. The overall time for each case took around 200 hours wall o'clock, including pre-processing, simulation and post-processing.

\subsection{D printing experiments and X-ray $\mu C T$ scans}

To validate the computational model, $3 \mathrm{D}$ printing experiments of discontinuous carbon fibre-reinforced polymer were carried out on a Prusa i3 MK3S+ printer using a printing material Onyx ${ }^{\circledR}$ from Markforged ${ }^{\circledR}$. The material data sheet has shown that Onyx ${ }^{\circledR}$ filament has diameter of $1.75 \mathrm{~mm}$ and consists of polycaprolactam (PA6) and short T300 carbon fibre [32]. The thermal properties of Markforged ${ }^{\circledR}$ ONYX were characterised in the previous study [33]. The glass transition temperatures $\left(T_{g}\right)$, crystallisation temperature $\left(T_{c}\right)$ and melting point $\left(T_{m}\right)$ are $27^{\circ} \mathrm{C}, 161^{\circ} \mathrm{C}$ and $197^{\circ} \mathrm{C}$, respectively. In our previous study [34], a X-ray microtomography $(\mu \mathrm{CT})$ scan of the intact filament was conducted, with an accelerating voltage of $80 \mathrm{kV}$ and a power of $7 \mathrm{~W}$. The exposure time and 
effective pixel size for each scan can be found in [34]. It demonstrated that it has a mean fibre length of $0.12 \mathrm{~mm}$, an average fibre diameter $7 \mu \mathrm{m}$ and a fibre volume fraction of about $13.34 \%$. The $\mu \mathrm{CT}$ scan also shows that the short carbon fibres are uniformly distributed and most of them are aligned with the longitudinal direction of the filament. The tensor component $a_{Z z} \mathrm{a}_{\mathrm{zz}}$ is about 0.9 in the raw filament (z-axis direction is the flow direction). The printing parameters of short carbon fibre-reinforced composites are listed in Table 1.

The internal geometry of the nozzle is essential for the configuration of the computational model, so a $\mu \mathrm{CT}$ scan of the nozzle was also carried out, as shown in Fig. 1a. It can be seen that the inner diameter of the nozzle is $2 \mathrm{~mm}$, and it is reduced to $0.45 \mathrm{~mm}$ in the outlet with a certain slope, as indicated in Fig. 2a. A composite sample was taken from the nozzle (see Fig. 1b) and scanned to obtain the microscopic information of fibre distributions, which will be used for the validation of the computational model.

\subsection{Validations of the coupled CFD-DEM modelling}

A schematic diagram of the computational domain is shown in Fig. 2a which contains two cylinders and a conical part inbetween them. Geometry of the domain is identical to that measured by the $\mu \mathrm{CT}$ scan in Fig. 1. For the inlet at the top, a constant fluid velocity $0.0012 \mathrm{~m} / \mathrm{s}$ is given. For the outlet at the bottom, a zero-pressure outlet boundary condition is imposed. The DEM particles are automatically removed as soon as they leave the nozzle outlet to save the computational cost. Solid walls, representing the internal walls of the nozzle, are set as non-slipping for both two phases. The model is first validated against the above experimental data for the Onyx ${ }^{\circledR}$ composite filament. Two other fibres with different lengths ( $L$ $=0.24 \mathrm{~mm}$ and $L=0.35 \mathrm{~mm}$ ) are considered in the later parametric studies. Fig. $2 \mathrm{~b}$ shows the cylinder-like fibres constructed by 17, 34 and 51 bonded spheres using DEM, representing a fibre length of $0.12 \mathrm{~mm}, 0.24 \mathrm{~mm}$ and 0.35 $\mathrm{mm}$, respectively. The bond stiffness is calculated according to the shear stiffness ( $G=15 \mathrm{GPa})$ and Poisson's ratio ( $v=$ $0.2)$ of the T300 carbon fibre. Particle density is set to be the same as T300 $\left(\rho=1600 \mathrm{~kg} / \mathrm{m}^{3}\right)$. The bonds between the spheres are not allowed to break in the present model to reduce the computational cost as the current study is focused on the fibre flow, in particular fibre bridging instead of fibre breakage. The process is considered to be isothermal without heat transfer. The simulations are performed using ANSYS-Fluent/ EDEM software.

The main parameters used in the numerical simulations are listed in Table 2. Identical to the experimental settings, the viscosity of the PA6 resin is set as $\mu_{f}=120 \mathrm{~Pa} \cdot \mathrm{s}$, and the vertically aligned fibres are gradually and randomly generated until reaching a volume fraction $V_{f}$ of $13.34 \%$. Fig. 3 shows the CT images and numerical results of fibre distributions in the respective representative areas of the nozzle. For the accurate result of quantitative analysis, the image processing was repeated three times when determining the fibre volume fraction at different representative areas. The fibre volume fraction alters from $13.34 \%$ in the raw filament to $12.60-15.83 \%$ in the in-nozzle melted filament, wherein chopped carbon fibres are re-distributed inside the nozzle in five representative areas [34]. The local excess of matrix in section I may result from both shear re-orientation between core and edge and the strong re-orientation at the entrance [35]. It also implies that the fibre fraction of the central region is initially close to the nominal value but increases gradually with the re-orientation of its outer regions of the melt flow. It can be seen that the general trend predicted by the numerical model agrees very well with the experimental observation. The fibre orientations in physical experiments are a little more disordered than that in the numerical simulations, especially in area V. The discrepancy could be due to the difference in the initial fibre distribution. In the numerical simulations, all the carbon fibres are initially set aligned with the longitudinal direction in the nozzle while in the physical experiments the fibres are not perfectly aligned in the nozzle cavity, e.g. the fibres are more misaligned in the constraint spaces such as area V. Quantitative comparisons of $V_{f}$ are shown in Fig. 4, which indicate an excellent agreement between the numerical results and the experimental data. The average error is approximately $2.81 \%$, providing a strong evidence that the adopted CFD-DEM model is capable of simulating this multiphase flow problem in $3 \mathrm{D}$ printing of composites.

\section{Parametric studies under different printing conditions}

\subsection{Occurrence of nozzle clogging}

The main objective of this work is to investigate the occurrence of nozzle clogging caused by fibre bridging in the
Table 1 The printing parameters of short carbon fibre-reinforced composites

\begin{tabular}{lllllll}
\hline $\begin{array}{l}\text { Printing } \\
\text { temperature }\end{array}$ & $\begin{array}{l}\text { Bed } \\
\text { temperature }\end{array}$ & $\begin{array}{l}\text { Printing } \\
\text { speed }\end{array}$ & $\begin{array}{l}\text { Off- } \\
\text { distance }\end{array}$ & $\begin{array}{l}\text { Feed rate of } \\
\text { filaments }\end{array}$ & $\begin{array}{l}\text { Filament } \\
\text { diameter }\end{array}$ & $\begin{array}{l}\text { Nozzle } \\
\text { diameter }\end{array}$ \\
\hline $275{ }^{\circ} \mathrm{C}$ & $90{ }^{\circ} \mathrm{C}$ & $60 \mathrm{~mm} / \mathrm{s}$ & $0.1 \mathrm{~mm}$ & $1.2 \mathrm{~mm} / \mathrm{s}$ & $1.75 \mathrm{~mm}$ & $0.45 \mathrm{~mm}$ \\
\hline
\end{tabular}


Fig. 1 a $\mu \mathrm{CT}$ scan of the nozzle and $\mathbf{b}$ in-nozzle melted sample taken from the nozzle (red box) [34]

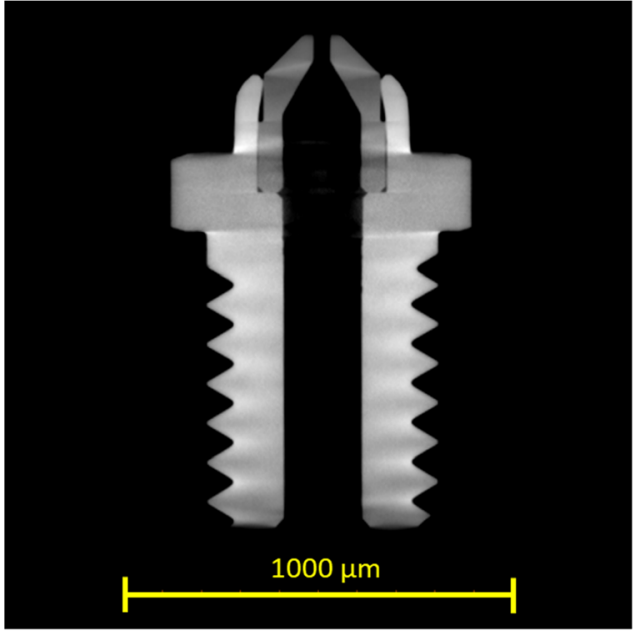

(a)

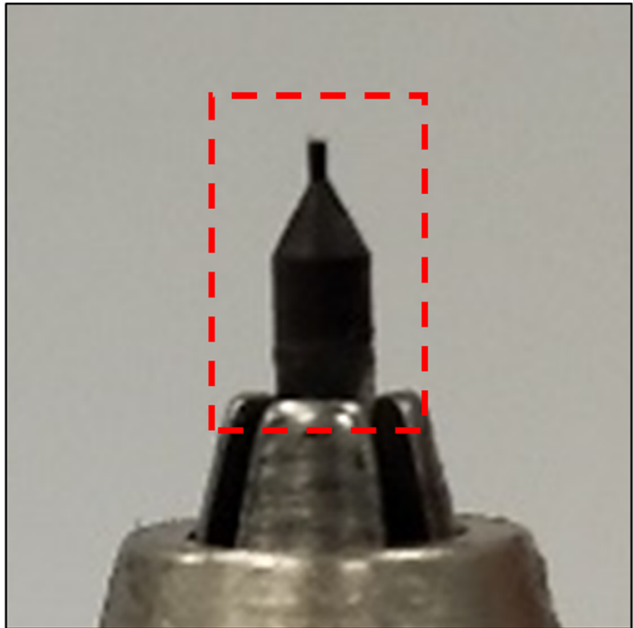

(b) nozzle under different printing conditions. The most influential factors for nozzle clogging are likely to be fibre length, fibre volume fraction, polymer properties and their combinations. As the nozzle has a diameter of $0.45 \mathrm{~mm}$, the maximum fibre length to be simulated is set as $L=0.45 \mathrm{~mm}$, with other three different lengths in-between $0.12 \mathrm{~mm}$ and $0.45 \mathrm{~mm}$. Besides Markforged PA6, two other representative polymer matrix, Arkema Elium 150 and Victrex PEEK 381G, with two significantly different viscosity and density values are also selected for comparisons. The fibre volume fraction $V_{f}=$ $13.34 \%$ in Markforged Onyx ${ }^{\circledR}$ T300/PA6 is set as a baseline and two higher $V_{f}$ values are selected as a higher fibre concentration which would be more desirable in practice to achieve better mechanical performance of the printed composites.

Corresponding numerical results are summarised in Table 3. If the simulation is successfully completed with continual flow of fibres through the nozzle outlet, it is considered that there is no fibre bridging and thus no nozzle clogging. On the contrary, if the fibres are gradually clogging in the nozzle and only polymer resin flows through the nozzle outlet, the simulation is terminated (due to an abrupt change of the concentration of DEM particles in the sharply narrowed region) and it is considered as an occurrence of fibre bridging and nozzle clogging.

As can be seen in Table 3, no bridging occurs for $L=$ $0.12 \mathrm{~mm}$ whereas bridging occurs for $L=0.45 \mathrm{~mm}$ in all simulated cases. For those fibres with a medium length, bridging occurs conditionally. At a relatively short fibre length $L=$ $0.24 \mathrm{~mm}$, low viscosity of the polymer matrix (i.e. Arkema Elium 150) is found to be effective for eliminating the clogging issue at a very high fibre concentration $V_{f}=26.68 \%$. However, the fibre length becomes more dominating when longer fibres are used (e.g. $L=0.35 \mathrm{~mm}$ and beyond), and the clogging is largely independent on the viscosity of the
Fig. 2 a Sketch of the computational domain and $\mathbf{b}$ three cylinder-like fibres with different length

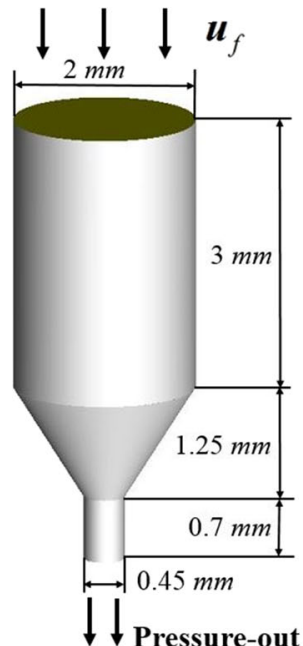

(a)

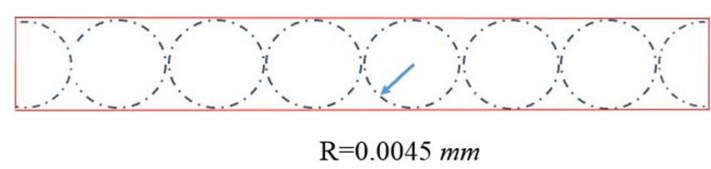

00000000000000006

$\mathrm{L}=0.12 \mathrm{~mm}$

$\mathrm{L}=0.24 \mathrm{~mm}$

$\mathrm{L}=0.35 \mathrm{~mm}$ 
Table 2 Numerical parameters used in the CFD-DEM simulations

\begin{tabular}{lll}
\hline Term & Parameter & Value \\
\hline Polymer matrix & Density $\left(\mathrm{kg} / \mathrm{m}^{3}\right)$ & $1010,1150,1300$ \\
& Viscosity $(\mathrm{Pa} \cdot \mathrm{s})$ & $0.1,120,300$ \\
Carbon fibre & Inlet velocity $(\mathrm{m} / \mathrm{s})$ & 0.0012 \\
& Fibre length $(\mathrm{mm})$ & $0.12,0.24,0.35,0.45$ \\
& Initial fibre volume fraction $(-)$ & $13.34 \%, 20.01 \%, 26.68 \%$ \\
& Density $\left(\mathrm{kg} / \mathrm{m}^{3}\right)$ & 1600 \\
& Shear's modulus $(\mathrm{GPa})$ & 15 \\
& Poisson's ratio (-) & 0.2 \\
\hline
\end{tabular}

polymer matrix. In addition, the use of such longer fibres imposes a strong constraint on the fibre volume fraction, with occurrence of nozzle clogging for both cases of $V_{f}=20.01 \%$ and $26.68 \%$. Further increase of fibre length to $L=0.45 \mathrm{~mm}$ results in nozzle clogging even at a very low fibre volume fraction, i.e. $V_{f}=13.34 \%$. This indicates that there is a strong correlation between fibre length and fibre volume fraction, and there would be a scope for optimising the combination of these two factors to mitigate the risk of nozzle clogging. Therefore, a more detailed and quantitative study of the fibre flow through the entire printing process is carried out in the next section.

\subsection{Effects of fibre length and fibre volume fraction}

Fig. 5 shows the distributions of $V_{f}$ in different representative areas for the 3D printing of T300/PA6 composites. From all these figures, it can be seen that the $V_{f}$ in areas I and II of the nozzle cavity are very close to the initial $V_{f}$. The flow rate is stable in the nozzle cavity and thus $V_{f}$ is not substantially affected. In contrast, a considerable increase of $V_{f}$ in areas III and IV can be observed as a result of the sharply narrowed nozzle cross-section in the nozzle aperture. This phenomenon becomes more paramount for longer fibres with a large initial $V_{f}$ as shown in Figs. $5 \mathrm{~b}$ and c. Note that a very large value of $V_{f}$ in areas III and IV may indicate the occurrence of fibre bridging, which also results in an extremely low $V_{f}$ in area $\mathrm{V}$ as shown in Fig. 5c when the initial $V_{f}$ is $26.68 \%$.

A typical bridging phenomenon in the evolution of fibre flow for $L=0.24 \mathrm{~mm}$ and initial $V_{f}=26.68 \%$ is given in Fig. 6 . It can be seen that as the fibres enter the shrinking region, the fibre orientation in area III is changed substantially from vertical to inclining. Severe interlocking takes place before these inclining fibres entering area V. Once the interlocking structure is strong enough to support the weight of above fibres, fibre bridging is formed and no more fibres can pass through the nozzle aperture to the nozzle outlet. As a result, the $3 \mathrm{D}$ printing process is terminated due to the clogging in the nozzle and the sudden rise of pressure in nozzle inlet, which prevents further feeding of the filament. Therefore, the current numerical results recommend that it is critical to control the fibre orientation in the shrinking region to prevent fibre bridging.

The occurrence of bridging is related to the average fibre (i.e. DEM particle) velocity in the nozzle as shown in Fig. 7. Recall that each fibre is formed by a group of spheres; thus, the average particle velocity is a statistical representation of the fibre flow. It can be observed from Fig. 7a that average particle velocities in all the cases show quite similar trends, i.e. increasing at first (due to gravity), then dropping (due to the
Fig. 3 Fibre distributions in different representative areas (I to $\mathrm{V})$ : a $\mu \mathrm{CT}$ images [34] and $\mathbf{b}$ numerical results

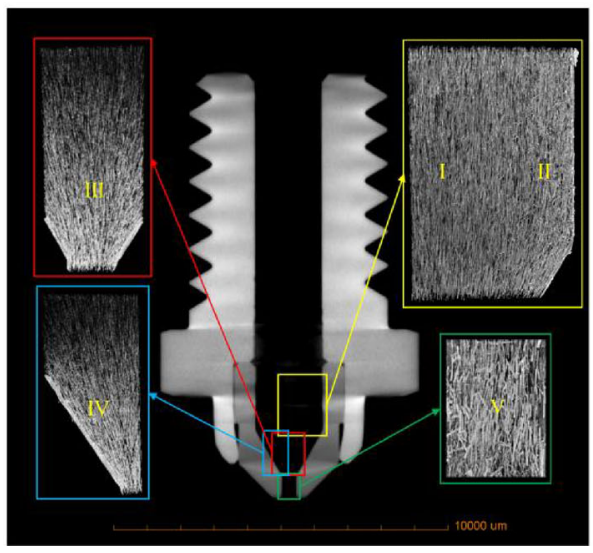

(a)

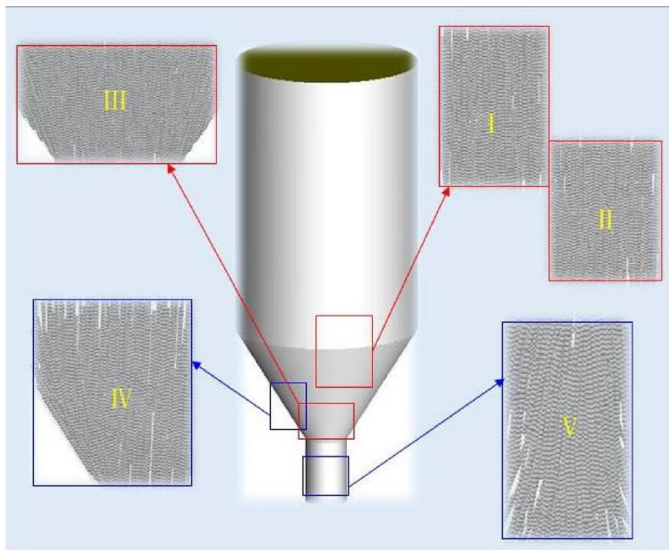

(b) 


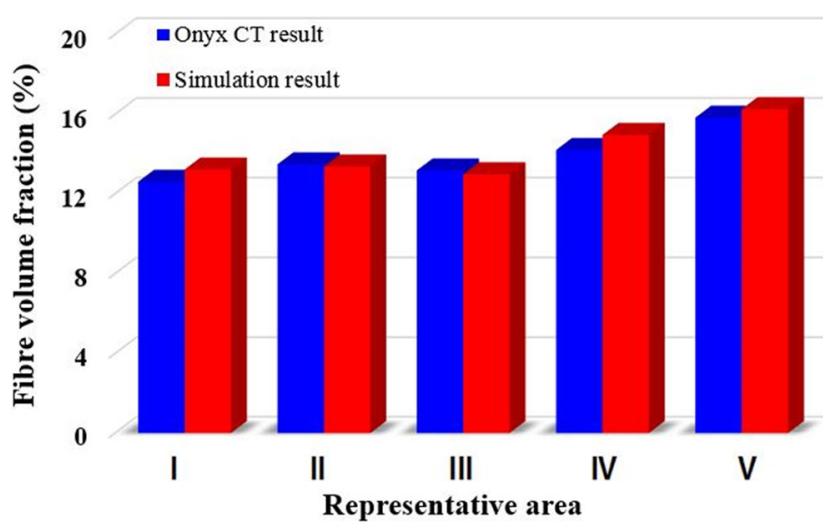

Fig. 4 Comparison of fibre volume fractions in different representative areas

obstruction of the shrinking section) and finally reaching an almost constant value (due to the narrow section in the nozzle outlet). In this study, nozzle clogging is regarded to take place when the constant value is lower than $0.5 \mathrm{~mm} / \mathrm{s}$. It is seen that the 3D printing processes can run well when $L=0.12 \mathrm{~mm}$ regardless of the initial $V_{f}$. This means that adopting shorter fibres is beneficial for the fluidity at the same initial $V_{f}$ and would not cause fibre bridging even with high initial $V_{f}$. When fibre length $L=0.24 \mathrm{~mm}$ is used as shown in Fig. 7b, it can be seen that the particle flow is not terminated with the increase of the initial $V_{f}$ until it reaches $26.68 \%$ and the average particle velocity becomes very low afterwards. Low velocities are commonly observed when the fibre length further increases to $L=0.35 \mathrm{~mm}$ as shown in Fig. 7c. Long fibres flow very slow even with a low initial $V_{f}$. Therefore, it can be concluded that the fibre length and the initial $V_{f}$ have a combined influence on the 3D printing process. Since a long fibre and high initial $V_{f}$ are favoured, the current numerical results suggest to adopt the case of $L=0.24 \mathrm{~mm}$ with initial $V_{f}=20.01 \%$ or $L=$ $0.35 \mathrm{~mm}$ with initial $V_{f}=13.34 \%$ for Markforged PA6 using the specific nozzle herein. Furthermore, it is worth noting that the distributions of fibre volume fraction and average particle velocity in the other two polymer systems show quite similar characteristics as in Figs. 5 and 7, and thus are not duplicate.
Finally, it is indicated from the current numerical results that fibre bridging actually takes place in areas III and IV, so it is necessary to carry out a microscale analysis on the particle structure in these areas to further investigate the mechanisms. For the same reason, the analysis is only carried out for Markforged PA6 but all the findings would be valid for Arkema Elium 150 and Victrex PEEK 381G.

\subsection{Microscale analysis on the particle structure}

Based on the observations in Fig. 6, area IV is of interest and the distribution of coordination number $(C N)$ in this area is shown in Fig. 8. $C N$ of a DEM particle is defined as the number of surrounding particles contacting with it. Therefore, overall distribution of $C N$ is a good indicator to show the packing structure of particles. Fig. 8a presents the probability density function $(P D F)$ of $C N$ in area IV for different study cases, from which it can be seen that the $C N$ curves for all these cases show a Gaussian-like profile. For each fibre length (and therefore different number of spheres for the fibre), with the increase of the initial $V_{f}$, the $C N$ curves shift parallel to the larger $C N$ slightly. This is reasonable because an increase of the initial $V_{f}$ leads to more potential contacts in a constrained space. For a given initial $V_{f}$ it is interesting to see that the peak positions of these $C N$ curves are not influenced by the increase of the fibre length. Normally, longer fibres would have larger $C N \mathrm{~s}$ in a dense packing system due to their larger surfaces for contacting with more other particles. However, that seems not the actual case here mainly because the fibres are almost parallelly distributed in area IV. There are approximately four other fibres around each fibre and that is why the peak values of all the $C N$ curves are located at four. Figs. 8b, $\mathrm{c}$ and d provide the position of the DEM particles which are coloured by their $C N$ s. It can be found that each sphere has $|C N|$ cylinders which present the interactions among the particles. The overall distribution of $C N$ in area IV is not much influenced by the fibre length or the initial $V_{f}$. Since the consistency of fibre orientations in area IV is also not influenced by the nozzle

Table 3 Occurrence of fibre bridging under different printing conditions ( $\circ$ for non-bridging, $\times$ for bridging)

\begin{tabular}{|c|c|c|c|c|c|c|c|c|c|}
\hline Polymer matrix & \multicolumn{3}{|c|}{ Arkema Elium 150} & \multicolumn{3}{|c|}{ Markforged PA6 } & \multicolumn{3}{|c|}{ Victrex PEEK $381 G$} \\
\hline Viscosity $\left(\mu_{f}\right)$ at elevated temperature & \multicolumn{3}{|l|}{$\begin{array}{l}0.1 \mathrm{~Pa} \cdot \mathrm{s} \\
\left(25^{\circ} \mathrm{C}\right)\end{array}$} & \multicolumn{3}{|l|}{$\begin{array}{l}120 \mathrm{~Pa} \cdot \mathrm{s} \\
\left(275^{\circ} \mathrm{C}\right)\end{array}$} & \multicolumn{3}{|l|}{$\begin{array}{l}300 \mathrm{~Pa} \cdot \mathrm{s} \\
\left(420^{\circ} \mathrm{C}\right)\end{array}$} \\
\hline Density $\left(\mathrm{kg} / \mathrm{m}^{3}\right)$ & \multicolumn{3}{|l|}{1010} & \multicolumn{3}{|l|}{1150} & \multicolumn{3}{|l|}{1300} \\
\hline \multirow[t]{2}{*}{$L(\mathrm{~mm})$} & \multicolumn{9}{|l|}{$V_{f}$} \\
\hline & $13.34 \%$ & $20.01 \%$ & $26.68 \%$ & $13.34 \%$ & $20.01 \%$ & $26.68 \%$ & $13.34 \%$ & $20.01 \%$ & $26.68 \%$ \\
\hline 0.12 & ० & $\circ$ & $\circ$ & $\circ$ & $\circ$ & ○ & $\circ$ & $\circ$ & $\circ$ \\
\hline 0.24 & $\circ$ & $\circ$ & $\circ$ & $\circ$ & $\circ$ & $x$ & $\circ$ & ○ & $x$ \\
\hline 0.35 & $\circ$ & $x$ & $x$ & $\circ$ & $x$ & $x$ & $\circ$ & $x$ & $x$ \\
\hline 0.45 & $x$ & $x$ & $x$ & $x$ & $x$ & $x$ & $x$ & $x$ & $x$ \\
\hline
\end{tabular}



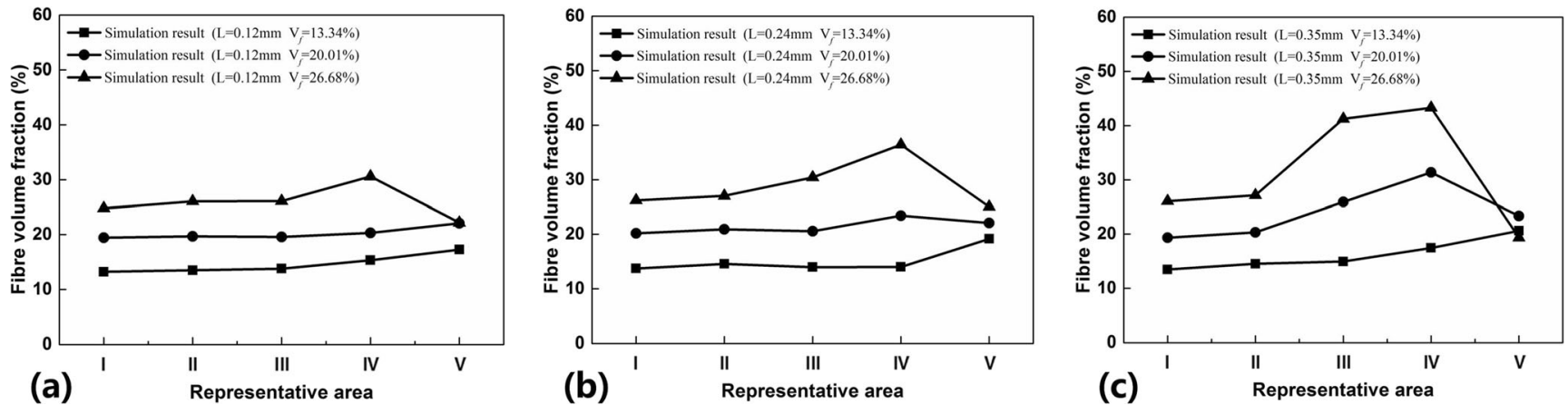

Fig. 5 Distribution of fibre volume fraction in five representative areas with different fibre length and initial fibre volume fraction when $\mu_{f}=120 \mathrm{~Pa} \cdot \mathrm{s}$ and $\rho=1150 \mathrm{~kg} / \mathrm{m}^{3}: \mathbf{a} L=0.12 \mathrm{~mm}, \mathbf{b} L=0.24 \mathrm{~mm}$ and $\mathbf{c} L=0.35 \mathrm{~mm}$

geometry, attention needs to be paid to the fibre bridging in area III to prevent nozzle clogging.

When the contact structure of the packed particles is obtained, it is useful to find out the contact forces at each contact point. Fig. 9 shows the $P D F$ of the contact forces and their fittings. It can be seen that the overall distribution trends of the contact forces are quite similar for all considered initial $V_{f}$ and fibre length. That is, most of the contact forces (i.e. $>60 \%$ ) are comparable and only a small proportion of larger forces exist. However, it is clear that the magnitude of the contact forces increases with both initial $V_{f}$ and fibre length. This is because the mass of a single fibre increases with its length. Larger particle mass leads to larger contact forces. Furthermore, there are more fibres with the increase of the initial $V_{f}$, and thus, the
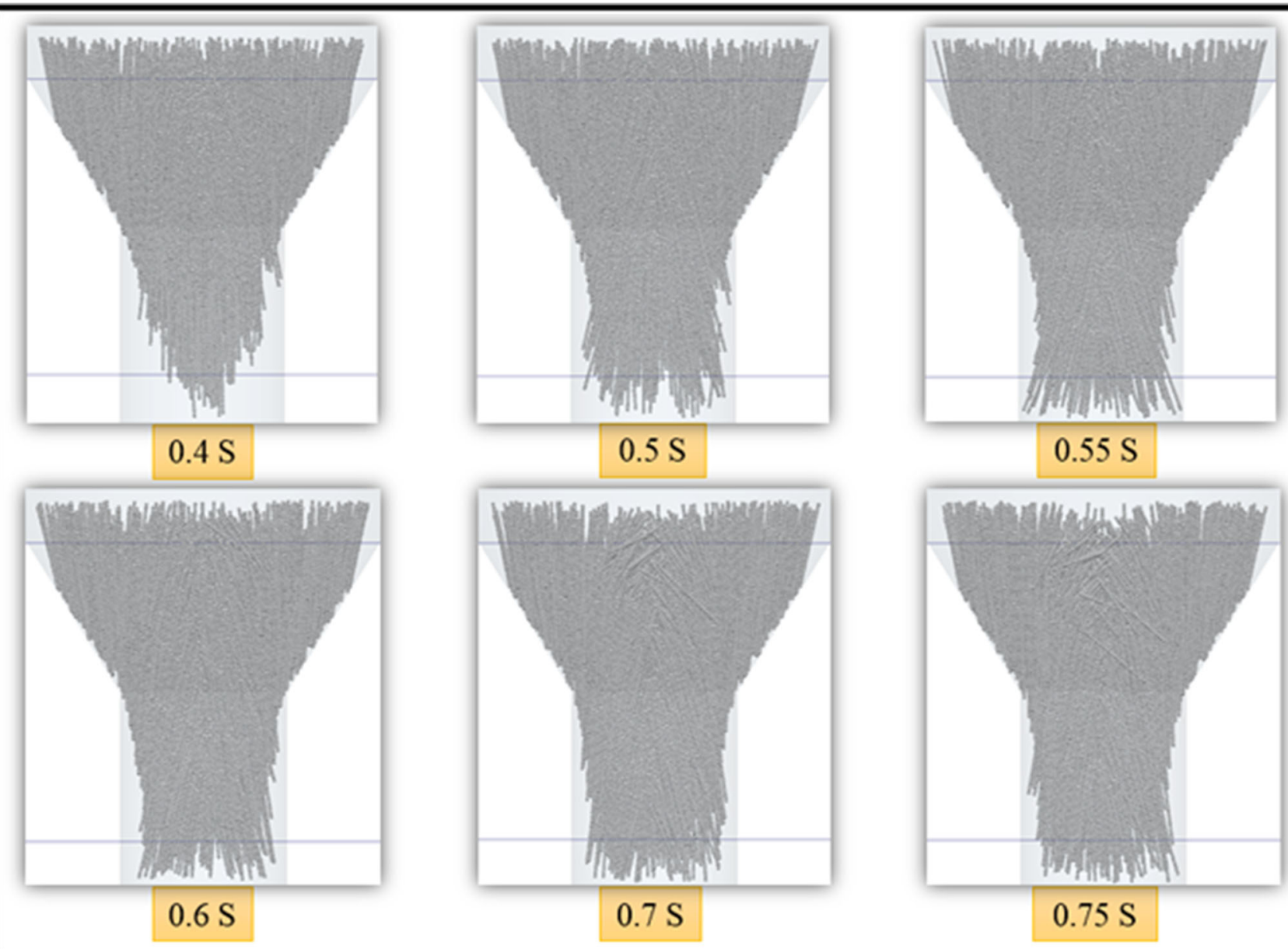

Fig. 6 Evolution of fibre flow for $L=0.24 \mathrm{~mm}$ and initial $V_{f}=26.68 \%$ (only fibres in the shrinking region are shown) 


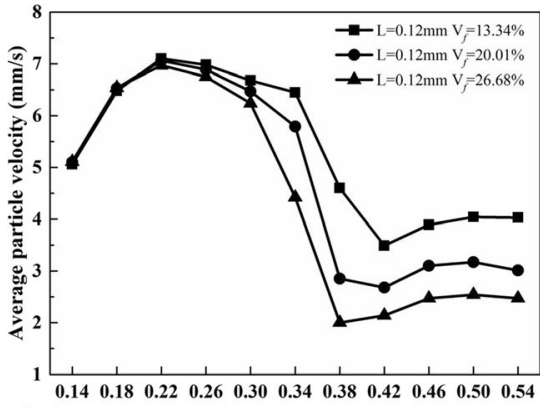

(a)

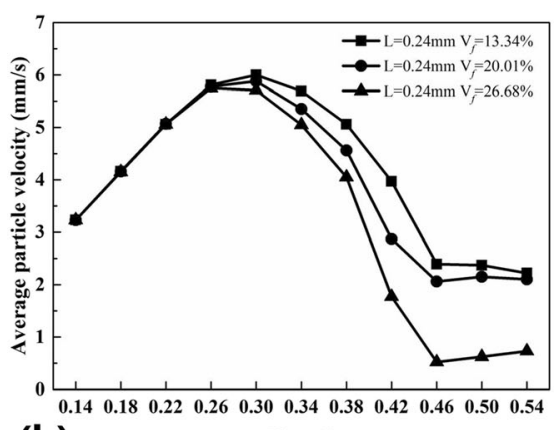

(b)

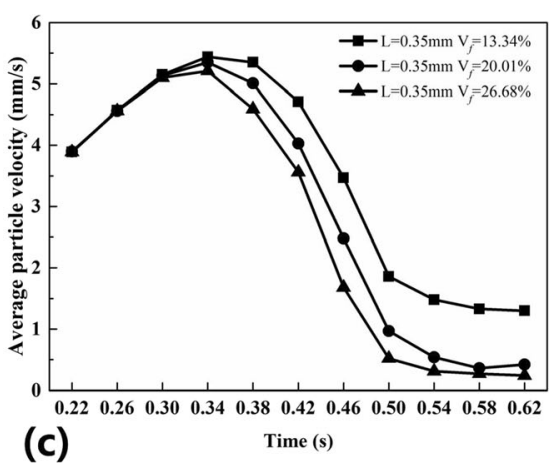

(c)

Fig. 7 The average particle velocity in the system with different fibre length and initial fibre volume fraction when $\mu_{f}=120 \mathrm{~Pa} \cdot \mathrm{s}$ and $\rho=1150 \mathrm{~kg} / \mathrm{m}^{3}$. a $L$ $=0.12 \mathrm{~mm}, \mathbf{b} L=0.24 \mathrm{~mm}$ and $\mathbf{c} L=0.35 \mathrm{~mm}$

packing structure becomes much denser, resulting larger contact forces.

\section{Proposed solutions to avoid nozzle clogging}

Above microscale analysis shows that the fibre distribution in area III is more sensitive to the fibre length and initial $V_{f}$. Therefore, to prevent the formation of fibre bridging and nozzle clogging, a cone sleeve insert is installed in area III, which is located in the nozzle aperture right above the shrinking region, as shown in Fig. 10. By changing the geometry of the insert, two plans (A and B) are proposed. The main difference between plans A and B lies on the size of the top and bottom circles and the sleeve height. It is the combined effect of these three parameters to change the sleeve angle from one to another. Numerical simulations on the nozzle with an insert are carried out based on the fibres $L=0.35 \mathrm{~mm}$ in Markforged PA6. It is believed that the same issues for shorter fibres and other polymer can be also resolved if the cone sleeve insert works for the longer fibres in Markforged PA6. Numerical results after these two designs are summarised in Table 4. It can be seen that nozzle clogging is successfully resolved by plan B rather than plan A. The average particle velocities for both designs are shown in Fig. 11 for different initial $V_{f}$. As shown, for both the two designs with two initial $V_{f}$, the general trends of the average particle velocity curves are quite similar with the original one. The main discrepancy takes place at the 'dropping' state when the fibres enter the nozzle aperture. Due to the existence of the insert, the average particle velocity drops faster than that in the original nozzle. This is especially true for plan A, in which the insert is found to retard the fibre sedimentation greatly and nozzle clogging cannot be avoided. Therefore, only when the cone sleeve insert is properly designed such as plan $\mathrm{B}$, the long fibres can flow into area $\mathrm{V}$ without any bridging taking place unlike the original nozzle and plan A.

Fig. 12 top shows the distributions of DEM particles for fibre length $L=0.35 \mathrm{~mm}$ and initial $V_{f}=26.68 \%$ for different geometries. It can be seen that plan B is advantageous mainly because the fibre orientations are essentially smoothed as compared to the original design. Due to this reason, the fluidity of the fibres is enhanced, and thus, the fibre bridging does not occur, making the movement of the fibres possible to the lower regions. Fig. 12 bottom shows the distributions of contact forces on the DEM particles. It can be seen that large forces mainly concentrate near the inclined walls of the nozzle aperture in all the three cases. However, quite different force distributions can be observed in the central region of the nozzle. For the original nozzle without any insert, large forces are found on those inclined fibres which lead to the formation of fibre bridging. For the nozzle with the cone sleeve insert of plan A, even larger contact forces are observed in the central region where the fibres do not have too much inclination. This is because the slope of the inclined wall of the insert is smaller than the nozzle aperture, which makes the fibres difficult to pass through the insert. At last, for the nozzle with the cone sleeve insert of plan $\mathrm{B}$, there are not many large forces in the central region and the $3 \mathrm{D}$ printing process runs quite smoothly.

Fig. 13 shows the percentage of the fibre orientations in which the inclined angle is defined as the angle between the fibre axis and the vertical direction. It is clearly seen that there are more 'vertical' fibres $\left(0^{\circ}<\right.$ inclined angle $\left.<15^{\circ}\right)$ in plan B than the other two designs. In other words, the initial orientation of the fibres is greatly maintained by the cone sleeve insert in plan $\mathrm{B}$, when they pass the shrinking region. Meanwhile, it can also be seen that there are more inclined fibres $\left(30^{\circ}<\right.$ inclined angle $\left.<45^{\circ}\right)$ in the original design than the two insert designs. The most 'horizontal' fibres $\left(45^{\circ}<\right.$ inclined angle $<90^{\circ}$ ) are found in the cone sleeve insert in plan A which of course leads to the highest risk of fibre bridging.

The new nozzle design enables the printing of short fibres with a longer length and a higher fraction, which will improve the mechanical properties of the CFRP composites, such as a 

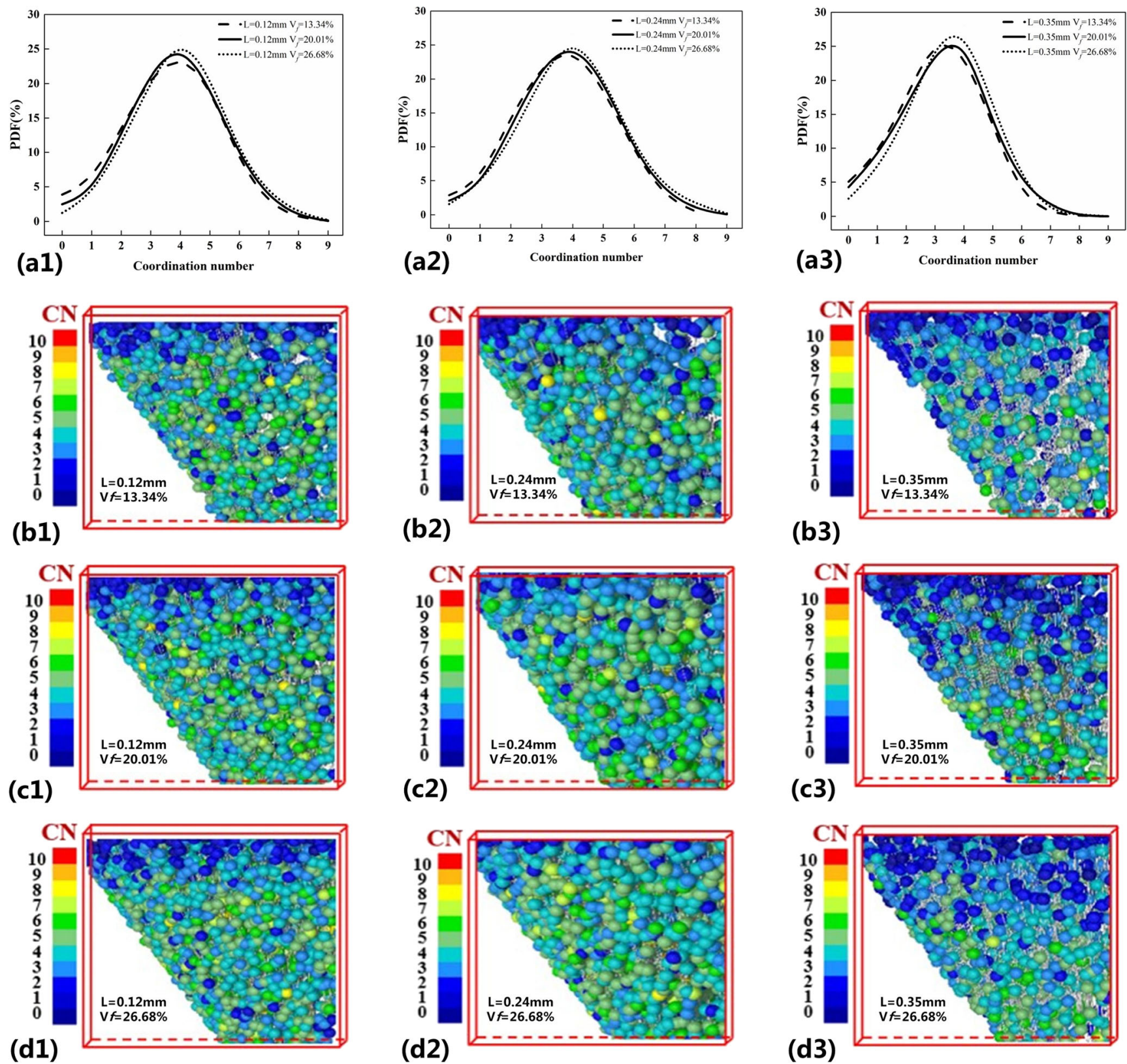

Fig. 8 Distribution of $C N$ in area IV for Markforged PA6: a fitting lines of the $P D F$ of $C N$, b distribution of $C N$ for $V_{f}=13.34 \%$, $\mathbf{c}$ distribution of particle coloured by their $C N$. The cylinders between particles represent $C N$ for $V_{f}=20.01 \%$ and d distribution of $C N$ for $V_{f}=26.68 \%$. The

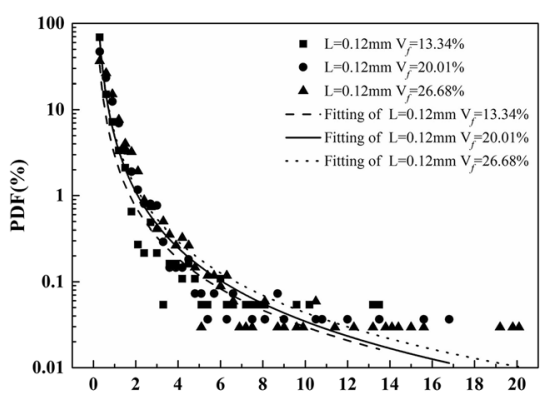

(a)

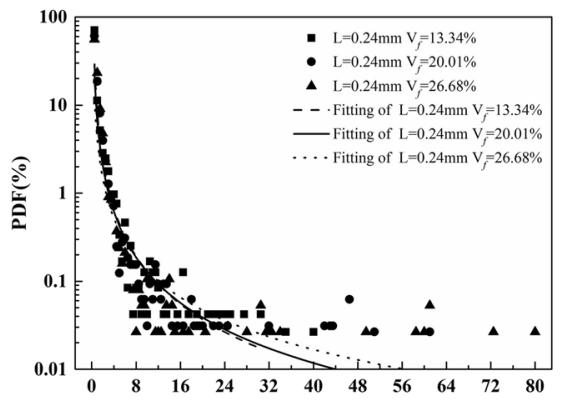

(b)

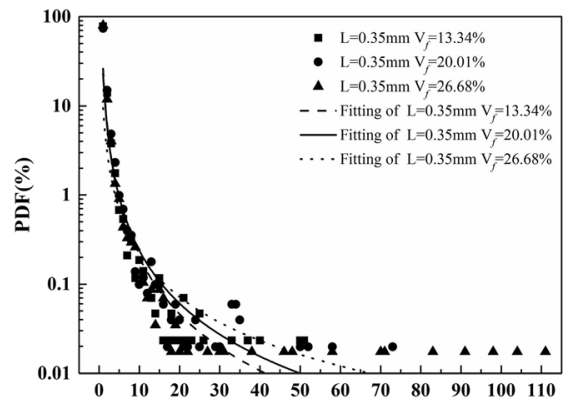

(c)

Total force $\left(10^{-7} \mathrm{~N}\right)$

Fig. 9 Probability density distributions of the contact forces and their fittings. a $L=0.12 \mathrm{~mm}$, b $L=0.24 \mathrm{~mm}$ and $\mathbf{c} L=0.35 \mathrm{~mm}$ 
Table 4 Likelihood of nozzle clogging for different insert designs ( 0 for non-bridging, $\times$ for bridging)

\begin{tabular}{llll}
\hline & Original & Plan A & Plan B \\
\hline Markforged PA6 & $\times$ & $\times$ & $\circ$ \\
0.35 mm-20.01\% & & & \\
Markforged PA6 & $\times$ & $\times$ & \\
0.35 mm-26.68\% & & & \\
\hline
\end{tabular}

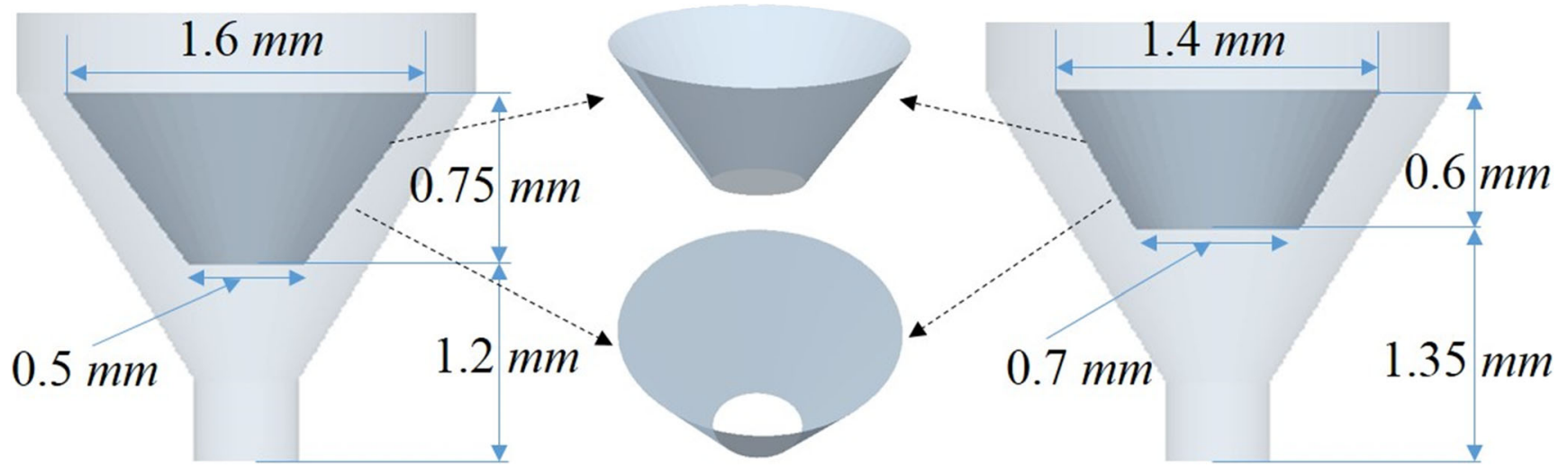

Fig. 10 Sketches of different cone sleeve inserts in the nozzle

higher stiffness/strength to weight ratio. As it can be used to print fibres in a broader range of lengths and weights, the performance of printed composites could be customised in local areas.

\section{Concluding remarks}

In this work, a coupled CFD-DEM model for the extrusionbased 3D printing process of discontinuous carbon fibre-

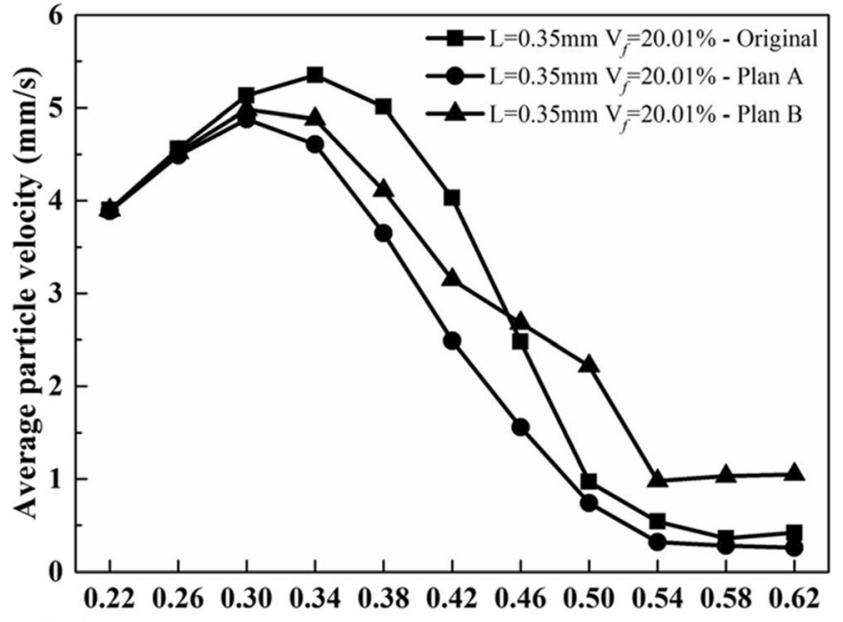

(a)

Time (s) reinforced polymer composites is developed and validated against experimental measurement data. Then three different fibre lengths and three different polymer resins considered are numerically investigated using a coupled CFD-DEM approach. Effects of fibre length, fibre volume fraction and polymer property on the $3 \mathrm{D}$ printing process are discussed and the occurrence of nozzle clogging is predicted. Microscale analysis on the fibre particle structure is conducted. Finally,

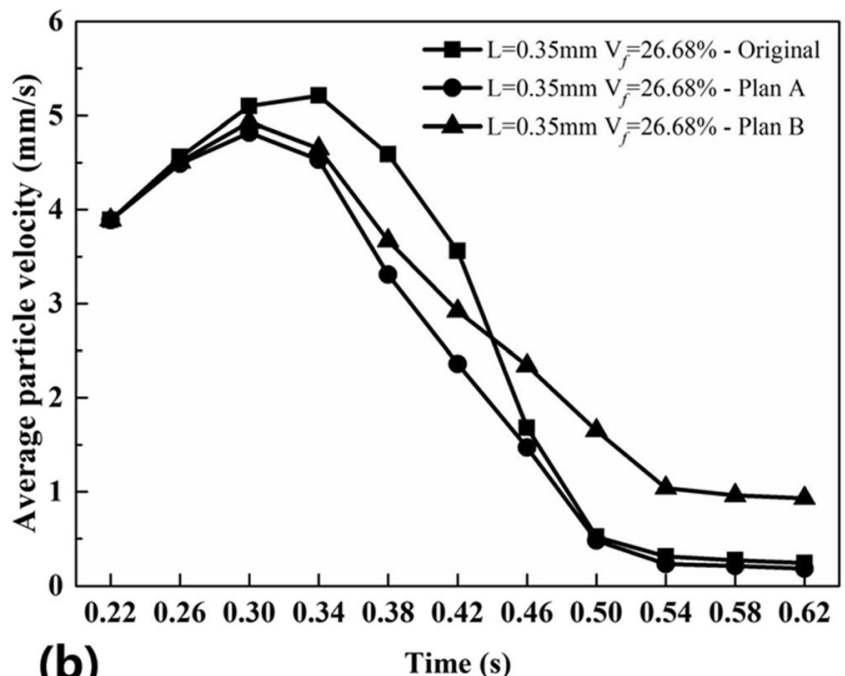

(b)

Time (s)

Fig. 11 The average particle velocity in the system with different plans: a $L=0.35 \mathrm{~mm}, V_{f}=20.01 \%$ and $\mathbf{b} L=0.35 \mathrm{~mm}, V_{f}=26.68 \%$ 


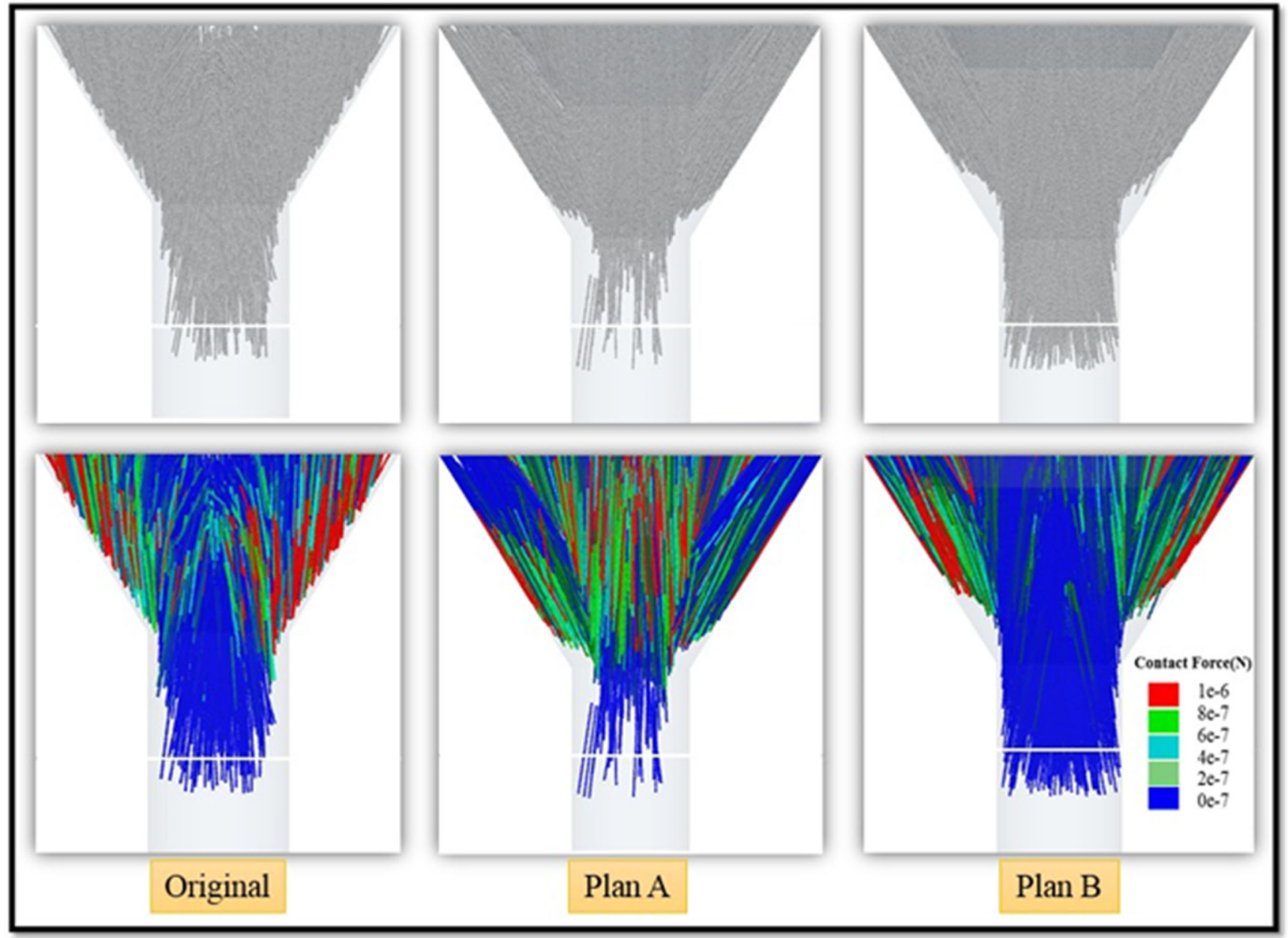

Fig. 12 Distributions of DEM particles (top) and DEM particles coloured by their contact forces (bottom) for $L=0.35 \mathrm{~mm}$ and initial $V_{f}=26.68 \%$ in different nozzles

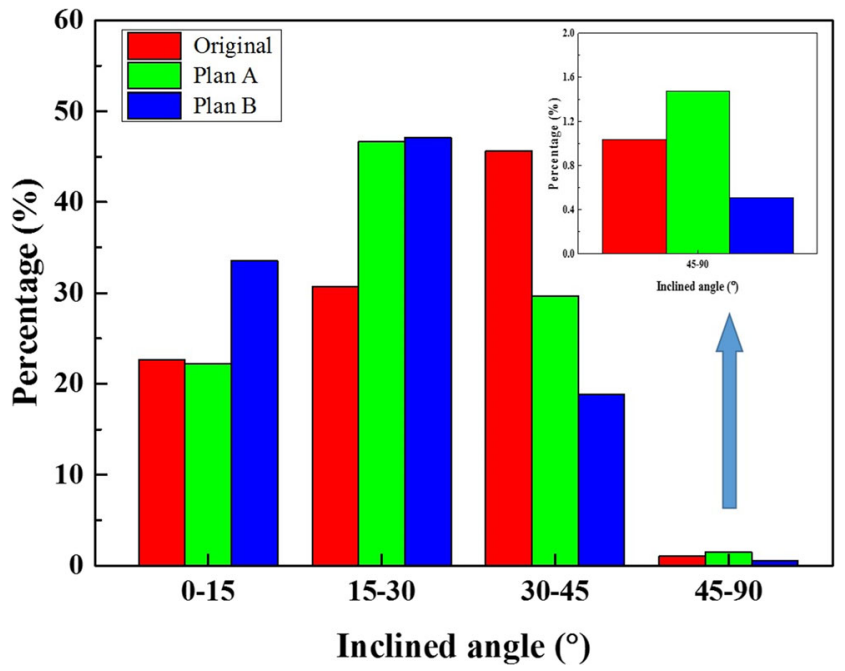

Fig. 13 The percentage of the orientations of fibre particles for $L=$ $0.35 \mathrm{~mm}$ and initial $V_{f}=26.68 \%$ in different nozzles potential solutions to avoid nozzle clogging are proposed and numerically evaluated. The study also serves a starting point to guide the future design and optimisation for 3D printing of composites with longer discontinuous fibres and high melting-viscosity polymer matrices. According to the numerical results, following conclusions can be drawn for the range of parameters considered in the current study.

(1) Adopting short fibre is profitable for the fluidity and avoiding nozzle clogging at the same initial $V_{f}$. At a relatively short fibre length $L=0.24 \mathrm{~mm}$, low viscosity of the polymer matrix (i.e. Arkema Elium 150) is effective for eliminating the clogging issue for very high fibre concentration $V_{f}=26.68 \%$.

(2) When long fibres are used (i.e. $L=0.35 \mathrm{~mm}$ and beyond), fibre length is the dominating factor for the mixture flow, and under this circumstance the clogging is largely independent on the viscosity of the polymer matrix. 
(3) A cone sleeve insert with a proper design and positioning could be a solution to the nozzle clogging, while manufacturing such small insert and combining it with the standard nozzle could be challenging. Therefore, further optimisation of such specific nozzle for printing long fibres is still needed when carrying out experimental tests.

Nomenclature $\quad C_{D}$, drag coefficient, $-; C N$, coordination number, $-; d_{v}$, equivalent diameter, $\mathrm{mm} ; D_{p, i}$, diameter of particle, $\mathrm{mm} ; F_{d, i j}$, viscous damping force, $\mathrm{N} ; F_{e, i}$, elastic force, $\mathrm{N} ; F_{f p}$, volumetric fluid-particle interaction force, $\mathrm{N} ; F_{p f, i}$, fluid-particle interaction force, $\mathrm{N} ; G$, shear stiffness, $\mathrm{Pa} ; I_{i}$, moment of inertia of particle, $\mathrm{kg} \cdot \mathrm{m}^{2} ; K_{v}$, total number of particles, $-; L$, length, $\mathrm{mm} ; m_{i}$, particle mass, $\mathrm{kg} ; n_{i}$, number of particles interacting with particle $i ; P$, pressure, $\mathrm{Pa} ; P D F$, probability density function; $R e_{i}$, Reynolds number for particle $i,-; t$, time, $\mathrm{s} ; T_{n, i j}$, torque by normal force, $\mathrm{N} / \mathrm{m} ; T_{r, i j}$, rolling friction torque, $\mathrm{N} / \mathrm{m} ; T_{t, i j}$, torque by tangential force, $\mathrm{N} / \mathrm{m} ; u_{f}$, fluid velocity, $\mathrm{m} / \mathrm{s} ; v_{i}$, particle velocity, $\mathrm{m} / \mathrm{s} ; V_{i}$, volume of particle $i, \mathrm{~m}^{3} ; V_{f}$, initial fibre volume fraction, $-; \Delta V$, computational cell of volume, $\mathrm{m}^{3}$

Greek letters $\beta$, fluid-particle interphase drag coefficient; $\delta_{k}$, the fluid Kronecker delta, $\mathrm{m} ; \varepsilon$, voidage, $-; \mu_{f}$, dynamic viscosity of fluid, $\mathrm{Pa} \cdot \mathrm{s} ; \nu$, particle Poisson ratio, $-; \rho$, density of fluid, $\mathrm{kg} / \mathrm{m} ; \tau$, stress tensor, $\mathrm{Pa} ; \varphi$, sphericity, $-; \boldsymbol{\omega}_{i}$, angular velocities, $\mathrm{rad} / \mathrm{s}$

Acknowledgements The authors are grateful to Dr Shengqiang Jiang (Xiangtan University) for his support on CFD-DEM simulations.

Funding The first author (HZ) would like to acknowledge the funding support from NSFC project (12072071) and Natural Science Foundation of Liaoning Province (2019-MS-125). The corresponding author (DY) would like to thank Royal Society for financial support of this project (IEC/NSFC/170418).

\section{Declarations}

Ethics approval Not applicable.

Consent to participate All authors have approved to participate.

Consent for publication The manuscript is approved by all authors for publication.

Conflict of interest The authors declare no competing interests.

Open Access This article is licensed under a Creative Commons Attribution 4.0 International License, which permits use, sharing, adaptation, distribution and reproduction in any medium or format, as long as you give appropriate credit to the original author(s) and the source, provide a link to the Creative Commons licence, and indicate if changes were made. The images or other third party material in this article are included in the article's Creative Commons licence, unless indicated otherwise in a credit line to the material. If material is not included in the article's Creative Commons licence and your intended use is not permitted by statutory regulation or exceeds the permitted use, you will need to obtain permission directly from the copyright holder. To view a copy of this licence, visit http://creativecommons.org/licenses/by/4.0/.

\section{References}

1. Degrieck J, Van Paepegem W (2001) Fatigue damage modeling of fibre-reinforced composite materials: review. Appl Mech Rev 54(4):279-300

2. Frketic J, Dickens T, Ramakrishnan S (2017) Automated manufacturing and processing of fiber-reinforced polymer (FRP) composites: an additive review of contemporary and modern techniques for advanced materials manufacturing. Additive Manufacturing 14:69-86

3. Zhang H, Yang D, Sheng Y (2018) Performance-driven 3D printing of continuous curved carbon fibre reinforced polymer composites: a preliminary numerical study. Compos Part B 151:256-264

4. Zhang H, Dickson AN, Sheng Y, McGrail T, Dowling DP, Wang C, Neville A, Yang D (2020) Failure analysis of 3D printed woven composite plates with holes under tensile and shear loading. Compos Part B 186:107835

5. Blok LG, Longana ML, Yu H, Woods BKS (2018) An investigation into $3 \mathrm{D}$ printing of fibre reinforced thermoplastic composites. Addit Manuf 22:176-186

6. Somireddy M, Singh CV, Czekanski A (2020) Mechanical behaviour of 3D printed composite parts with short carbon fiber reinforcements. Eng Fail Anal 107:104232

7. Zhong W, Li F, Zhang Z, Song L, Li Z (2001) Short fiber reinforced composites for fused deposition modeling. Mater Sci Eng A 301(2): $125-130$

8. Yu S, Hwang YH, Hwang JY, Hong SH (2019) Analytical study on the 3D-printed structure and mechanical properties of basalt fiberreinforced PLA composites using X-ray microscopy. Compos Sci Technol 175:18-27

9. Sang L, Han S, Li Z, Yang X, Hou W (2019) Development of short basalt fiber reinforced polylactide composites and their feasible evaluation for 3D printing applications. Compos Part B 164:629639

10. Ning F, Cong W, Hu Y, Wang H (2016) Additive manufacturing of carbon fiber-reinforced plastic composites using fused deposition modeling: effects of process parameters on tensile properties. J Compos Mater 51(4):451-462

11. Van de Werken N, Tekinalp H, Khanbolouki P, Ozcan S, Williams A, Tehrani M (2020) Additively manufactured carbon fiberreinforced composites: state of the art and perspective. Addit Manuf 31:100962

12. Kumar N, Jain PK, Tandon P, Pandey PM (2018) The effect of process parameters on tensile behavior of $3 \mathrm{D}$ printed flexible parts of ethylene vinyl acetate (EVA). J Manuf Process 35:317-326

13. Brenken B, Barocio E, Favaloro A, Kunc V, Pipes RB (2018) Fused filament fabrication of fiber-reinforced polymers: a review. Addit Manuf 21:1-16

14. Mohamed OA, Masood SH, Bhowmik JL (2015) Optimization of fused deposition modeling process parameters: a review of current research and future prospects. Adv Manuf 3(1):42-53

15. Goh GD, Yap YL, Tan H, Sing SL, Goh GL, Yeong WY (2020) Process-structure-properties in polymer additive manufacturing via material extrusion: a review. Crit Rev Solid State Mater Sci 45(2):113-133

16. Gunduz I, McClain M, Cattani P, Chiu G-C, Rhoads J, Son S (2018) 3D printing of extremely viscous materials using ultrasonic vibrations. Addit Manuf 22:98-103

17. Mei H, Ali Z, Yan Y, Ali I, Cheng L (2019) Influence of mixed isotropic fiber angles and hot press on the mechanical properties of 3D printed composites. Addit Manuf 27:150-158

18. Longana ML, Yu H, Lee J, Pozegic TR, Huntley S, Rendall T, Portter KD, Hamerton I (2019) Quasi-isotropic and pseudoductile highly aligned discontinuous fibre composites 
manufactured with the hiperdif (high performance discontinuous fibre) technology. Materials 12(11):1794-1806

19. Tekinalp HL, Kunc V, Velez-Garcia GM, Duty CE, Love LJ, Naskar AK, Blue CA, Ozcan S (2014) Highly oriented carbon fiber-polymer composites via additive manufacturing. Compos Sci Technol 105:144-150

20. Lewicki JP, Rodriguez JN, Zhu C, Worsley MA, Wu AS, Kanarska $\mathrm{Y}$ et al (2017) 3D-printing of meso-structurally ordered carbon fiber/polymer composites with unprecedented orthotropic physical properties. Sci Rep 7(1):1-14

21. Tseng P, Napier B, Zhao S, Mitropoulos AN, Applegate MB, Marelli B, Kaplan DL, Omenetto FG (2017) Directed assembly of bio-inspired hierarchical materials with controlled nanofibrillar architectures. Nat Nanotechnol 12(5):474-480

22. Raney JR, Compton BG, Mueller J, Ober TJ, Shea K, Lewis JA (2018) Rotational 3D printing of damage-tolerant composites with programmable mechanics. Proc Natl Acad Sci U S A 115(6):1198-1203

23. Le Ferrand H, Bouville F, Niebel TP, Studart AR (2015) Magnetically assisted slip casting of bioinspired heterogeneous composites. Nat Mater 14(11):1172-1179

24. Croom BP, Abbott A, Kemp JW, Rueschhoff L, Smieska L, Woll A et al (2021) Mechanics of nozzle clogging during direct ink writing of fiber-reinforced composites. Addit Manuf 37:101701

25. Wang JY, Xu DD, Sun W, Du SM, Guo JJ, Xu GJ (2019) Effects of nozzle-bed distance on the surface quality and mechanical properties of fused filament fabrication parts. IOP Conf Ser: Mater Sci Eng 479

26. Turner BN, Strong RJ, Gold S (2014) A review of melt extrusion additive manufacturing processes: I. Process design and modeling. Rapid Prototyp J 20(3):192-204

27. Papon MEA, Haque A, Sharif MAR (2017). Effect of nozzle geometry on melt flow simulation and structural property of thermoplastic nanocomposites in fused deposition modeling. In:
Proceedings of American Society for Composites. Conference, Conference 2017.

28. Heller BP, Smith DE, Jack DA (2016) Effects of extrudate swell and nozzle geometry on fiber orientation in fused filament fabrication nozzle flow. Addit Manuf 12:252-264

29. Heller BP, Smith DE, Jack DA (2019) Planar deposition flow modeling of fiber filled composites in large area additive manufacturing. Addit Manuf 25:227-238

30. Yang D, Wu K, Wan L, Sheng Y (2017) A particle element approach for modelling the $3 \mathrm{D}$ printing process of fibre reinforced polymer composites. J Manuf Mater Process 1(1):10

31. Gidaspow D (1994) Multiphase flow and fluidization: continuum and kinetic theory descriptions: Academic press

32. Walter R, Friedrich K, Gurka M (2018) Characterization of mechanical properties of additively manufactured polymers and composites. AIP conference proceedings: AIP Publishing LLC. p. 020033

33. Pascual-González C, Iragi M, Fernández A, Fernández-Blázquez JP, Aretxabaleta L, Lopes CS (2020) An approach to analyse the factors behind the micromechanical response of 3D-printed composites. Compos Part B 186:107820

34. Yang D, Zhang H, Wu J, McCarthy ED (2020). Fibre flow and void formation in 3D printing of short-fibre reinforced thermoplastic composites: an experimental benchmark exercise. Additive Manufacturing

35. Toll S, Andersson PO (1993) Microstructure of long-and short-fiber reinforced injection molded polyamide. Polym Compos 14(2):116 125

Publisher's note Springer Nature remains neutral with regard to jurisdictional claims in published maps and institutional affiliations. 